\title{
Supplying DC Electricity to the Isolated Dwellings through MPP Tracked PV System Based on Artificial Neural Network
}

\author{
Hussain Attia \\ American University of Ras Al Khaimah \\ Ras Al khaimah / United Arab Emirates \\ hattia@aurak.ac.ae
}

\begin{abstract}
The difficulties of the grid electricity supplying to certain locations like far, high lands, or countryside leads to concentrate on the solutions of the renewable photovoltaic stand-alone system supported by an efficient maximum power point tracker. In addition, the difficulties of the alternating current system which are represented by a complicated controller, system size, and high cost due to the necessity of involving an inverter, a high order filter and a step up or an insulation transformer. From this point of view, this paper presents a new solution of $10.8 \mathrm{~kW}$ PV system which combines between the high performance of the MPPT controller and the avoiding of the alternating parts by considering direct current home appliances. A study of loads' power requirements, PV matrix design of an isolated dwelling, a full electronic design of a DC-DC boost converter with a fast response MPPT controller based on an Artificial Neural Network (ANN) which is followed by Proportional Integral (PI) controller all are presented in this paper. The simulation results are collected through MATLAB/Simulink, and the system performance is evaluated and indicated the high effectiveness in terms of harvested power.
\end{abstract}

Keywords: Direct current appliance, power requirements, photovoltaic matrix, MPPT, artificial neural network, Proportional Integral PI controller, DC-DC boost converter, MATLAB/Simulink.

\section{Introduction}

Off-grid isolated/moveable dwelling represents an effective solution for supplying the required electricity to the far, or countryside locations due to the difficulty of reaching the alternating current AC grid. The stand-alone system is an equivalent concept to the off-grid system, through which many merits can be offered which are: reducing the negative effects of fossil fuels consumed in grid power station, and consequently reducing the size and the cost of the station infrastructure, avoiding the negative effects of grid power fluctuation, giving chance for living in the remote locations like high lands or countryside as an alternative. For off-grid solutions, solar energy is considered as one of the green renewable energy sources, this source is playing a major role to deliver the required electrical power for the isolated/moveable/individual/remote dwellings [1]-[2]. In terms of merits, solar energy source is characterized by the availability, the cheapness of the harvesting, the cleanliness and the easy harvesting through photovoltaic panels [3]-[4]. Whereas in terms of demerits, the effectiveness of the solar energy source is suffering from several factors such as the fluctuation in the irradiance and ambient temperature levels of the weather conditions, and weather dust. In addition to the limited daily hours of solar energy harvesting, this is leading to the necessity of using battery bank for energy storage purpose that to reuse the stored energy during the night hours or to manipulate the fluctuation of the solar energy source behaviour [1], [5]. Solar cell's function is converting the solar energy to electrical power. The level of the harvested solar energy and converted to load power is proportional with the irradiance level whereas inversely proportional with the ambient temperature. The behaviour of the solar panel with respect to the produced power is nonlinear due to the nonlinearity of the output current during the variation of the output voltage of the PV panel [6]-[7]. The arrangement of the solar cells' connection can be designed based on the required level of the output voltage and current [8]. In stand-alone PV system of electricity supplying to the AC appliances dwelling, there are two demerits represented by system complexity due to the needs of involving an inverter, a high order filter such as LCL or LLCL filter, and a step up or an insulation transformer. The second demerit is represented by a low level of the harvested power due to the missing of MPP working conditions. In both PV systems (stand-alone and grid connected), due to the nonlinearity behaviour of the PV panel in terms of the delivered power, many methods and algorithms are proposed in 
literature for guaranteeing the system work at the MPP location and for tracking this location during any weather condition that to harvest maximum power from the PV panel, array, or matrix [9]-[19].

The conventional algorithms of Incremental Conductance, Perturb \& Observe, and the short circuit current method all are presented in [9]-[10], the main demerits of the mentioned algorithms are the oscillated and the low tracking response. Due these demerits, researchers are focusing on studying and proposing an efficient algorithms. Fuzzy Logic Controller FLC is proposed in [11]-[13] as an effective, robust, and fast controller for MPP tracking function. Artificial Neural Networks ANN algorithm as a one of machine learning algorithms which is firstly proposed as an accurate, very fast response algorithms for different objectives researches [14]-[16]. Currently, ANN algorithm is adopted in many studies for MPPT aim [17]-[19]. In [17], an intelligent controller based on ANN is proposed to control a buck-boost DC-DC converter as part of PV system. A comparative study between two intelligent algorithms based on neural networks in to improve the PV system performance is explained in [18], whereas in [19], a Ph.D. research study shown a full study of the PV system performance through testing different MPPT algorithms including ANN. Then a new ANN algorithm was proposed as an intelligent controller for a water pump's DC motor.

By considering the above, and to have high performance PV system for electricity supplying to a remote dwellings, this study proposes a new solution which focuses on firstly adopting a direct current appliances of rated power reaches to $5 \mathrm{~kW}$ with additional energy saving through using the Light Emitting Diodes LED for lighting purpose [20]-[21], at the same time, designing an efficient MPP tracker through a certain designed ANN algorithm. Design of PV matrix, current and power curves of the PV matrix, and electronic design of the DC-DC converter, all are presented in this study.

\section{Details of Power Requirement}

The typical appliances for stand-alone solar energy supplied dwelling can be divided into two scale categories: low-scale dwelling which is considered as small-range power applications, and mid-scale dwelling which is considered as mid-range power applications. The appliances of the first scale are low consumed power appliances such as LED lighting lamps and other electronic devices of low consumed power such as LED/LCD or smart TVs, computer supplies, and portable chargers [22]. While mid-scale dwelling includes higher power range appliances such as fridges, airconditioners, and heaters or cockers, in addition to the low-scale appliances [23]-[24].

The proposed study focuses on mid-scale dwelling in sides of consumed power, and system requirements. Table 1 shows the adopted appliances and the details of the load power, daily duty hours, whereas Table 2 shows the specifications of the considered PV model (SL360TU-36MD).

Table 1: DC appliances for mid-scale dwelling.

\begin{tabular}{|c|c|c|c|}
\hline $\begin{array}{c}\begin{array}{c}\text { Electrical } \\
\text { Item }\end{array} \\
\end{array}$ & $\begin{array}{c}\text { DC Appliances } \\
\text { Rated Power }(\mathbf{W})\end{array}$ & $\begin{array}{l}\text { DC appliances } \\
\text { Daily Hours }\end{array}$ & $\begin{array}{l}\text { Daily } \\
\text { Watt } \cdot \text { Hour }\end{array}$ \\
\hline PV Module: (SL360TU-36MD) & $6 \times 360$ & 5 & 10800 \\
\hline $\begin{array}{c}\text { Battery Bank (BB) } \\
4 \times 12=48 \text { Volts of } 200 \text { A.H }\end{array}$ & $\begin{array}{c}\mathrm{I}_{\text {Normal Charging }}= \\
10 \% \text { of } 200 \mathrm{~A}=20 \mathrm{~A}\end{array}$ & $\begin{array}{l}5 \text { Hours for BB } \\
\text { Charging }\end{array}$ & $\begin{array}{c}=48 \mathrm{~V} \times 20 \mathrm{~A} \times 5 \mathrm{H} \\
=4800 \mathrm{~W} \cdot \mathrm{H}\end{array}$ \\
\hline LED Lamps & $4 \times 10$ & 6 & 240 \\
\hline Exhaust Fan & $2 \times 50$ & 1 & 100 \\
\hline Fridge & 150 & 6 & 900 \\
\hline Air Conditioner & 500 & 6 & 3000 \\
\hline Heater/Cooker & 600 & 1 & 600 \\
\hline \multicolumn{4}{|c|}{ Maximum required current $(\mathrm{A})$ for appliances $=\mathrm{P} / \mathrm{V}=(40+100+150+500+600) / 48=29 \mathrm{~A}$} \\
\hline \multicolumn{3}{|c|}{ Required Power (W) for appliance / Day } & 4840 \\
\hline \multicolumn{3}{|c|}{ Required Power (W) for BB charging / Day } & 4800 \\
\hline \multicolumn{3}{|c|}{ Maximum limit of the total required power / Day } & 9640 \\
\hline
\end{tabular}


Table 2: The specifications of the considered solar PV module (SL360TU-36MD), and PV array.

\begin{tabular}{|c|c|}
\hline PV Panel Parameter & Parameter Value \\
\hline Maximum Power $(\mathrm{W})$ & 360 \\
\hline Optimum Power Voltage $\left(V_{m p p}\right)$ & 39.26 \\
\hline Optimum Operating Current $\left(I_{m p p}\right)$ & 9.17 \\
\hline Open Circuit Voltage $\left(V_{o c}\right)$ & 46.59 \\
\hline Short Circuit Current $\left(I_{s c}\right)$ & 9.81 \\
\hline Module Efficiency $(\%)$ & 18.55 \\
\hline Tolerance Wattage $(\%)$ & $0 \sim+3 \%$ \\
\hline No. of Cells in panel & 72 \\
\hline Number of parallel lines $(N P)$ & 6 \\
\hline Number of series panels $(N S) /$ line & 1 \\
\hline Array power $\left(P_{m p p}\right)=6 \times 360 \mathrm{~W}$ & $2160 \mathrm{~W} \pm 3 \%$ \\
\hline
\end{tabular}

\section{PV System Description}

The proposed design considers mid-scale dwelling of direct current appliances which are consuming approximately 5 $\mathrm{kW}$ daily. The system is also able to deliver an additional power of $5 \mathrm{~kW}$ for battery bank (BB) charging, the BB stored power is designed to be equal to the daily power required for the DC appliances. So, to have an effective PV system, the harvested power through the PV panels should be greater than $10 \mathrm{~kW} \cdot \mathrm{H}$ per day. Because of that the designed PV array includes 6 panels of $360 \mathrm{~W}$ each and the selected PV module is SL360TU-36MD. Fig. 1 shows the block diagram of the proposed PV system, and the detailed design of the system. To guarantee an efficient and quick tracking response for MPP locations, a feed forward artificial neural network (ANN) is designed in this study to have an accurate reference voltage $V_{\text {ref }}$, this reference value enter to subtraction block to minus the actual PV panel voltage $V_{P V}$, the result represents an error signal. Proportional Integral (PI) controller is involved in the system design to soften the variation of the error signal. PI parameters are tuned to have suitable variation of duty cycle $D$ that to produce the Pulse Width Modulation (PWM) driving pulses by comparing the switching frequency triangle signal with the instantaneous DC level of duty cycle. These pulses are driving the converter which is controlling the DC load power based on the instantaneous level of duty cycle D. The converter is delivering a suitable DC link voltage for battery bank charger which is used to do normal charging of $10 \%$ of the BB capacity 200 A.H [25]. The focusing of this study will be on the details of the power requirements for DC appliances of the mid-scale dwelling. In addition, this study focuses on the challenge of designing an effective MPP tracker for the PV system through an artificial neural network, whereas the design of battery bank charger does not included in the presented paper.

\subsection{Photovoltaic Array}

The proposed arrangement of the selected PV panels of SL360TU-36MD are shown in Fig. 1 as PV array includes 6 parallel connected panels. The selected module is characterized by $18.55 \%$ efficiency, and output power of $360 \mathrm{~W}$ at maximum power point location as explained in Table 2. Based on the proposed arrangement of the PV array, it is noticeable that the output voltage of the array is the same of panel's voltage whereas the total current equals to the summation of the 6 PV panels due to the parallel connection, this leads to have total power of 6 times of the output power of one panel. 


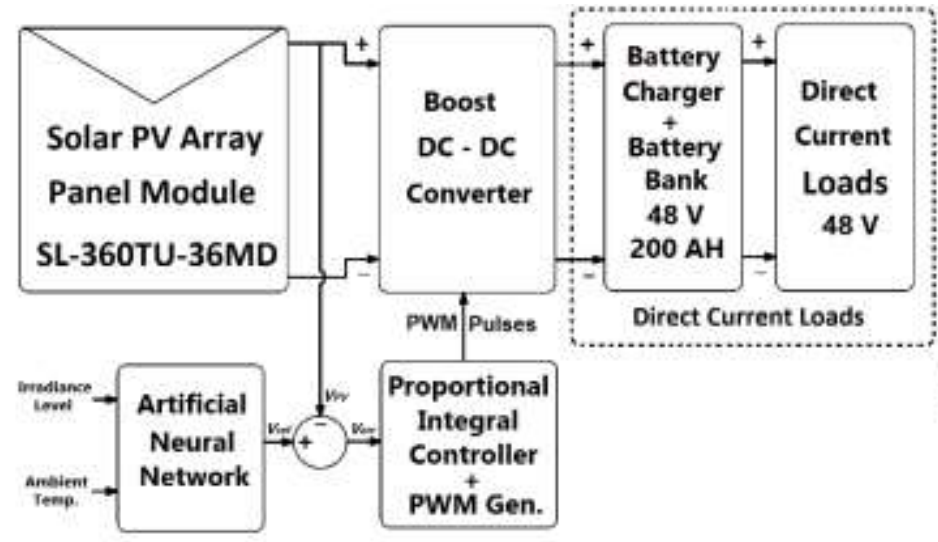

(a)

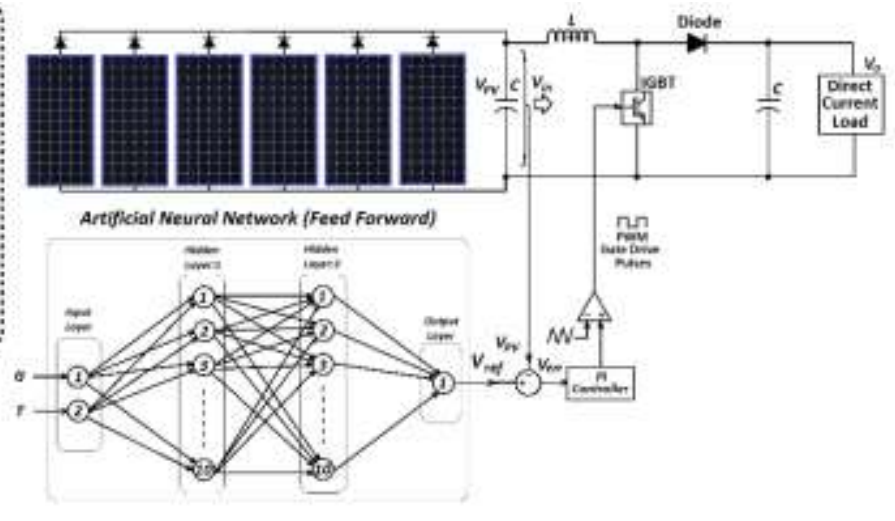

(b)

Fig. 1: Proposed PV system for isolated dwelling's DC appliances, (a) block diagram, (b) Detailed diagram.

The instantaneous level of the solar cell's output current is positively affected by the instantaneous level of the incident light whereas negatively affected by the instantaneous level of the ambient temperature. In addition, the variation of the output current is nonlinear with respect to the output voltage value, this leads to have nonlinear relation between the output power level and the output voltage. The equivalent circuit of the solar cell is illustrated in Fig. 2, whereas (1)-(5) are explaining the relations among the circuit's parameters: $I_{S C}$ is the short circuit current, $I_{D}$ is the diode current, $I_{P}$ is the parallel resistor current, $I_{P V}$ is the output PV current, $V_{P V}$ is the PV output voltage, $R_{P}$ is the parallel resistor, $R_{S}$ is the serial resistor, $G_{r}$ is the generation rate, $L_{n}$ and $L_{p}$ are the electronic and hole diffusion length, and $A$ is the solar cell area [10]-[13], [17]-[19], and [23]-[24]. The total level of the output voltage and current from the photovoltaic matrix can be calculated using (6)-(7). For output voltage increasing, the cells are needed to be serially connected, and for output current increasing, the cells are needed to be parallel connected. Based on the power requirement analysis of this study, the total number of the PV panels equals to 6 panels, which are connected in parallel way as shown in Fig. 1 that to have a current increment with keeping the output voltage as it is. Fig. 3 show the output current and power curves of PV panel module SL360TU-36MD with respect to the panel output voltage at different weather conditions of irradiance and ambient temperature. Fig. 4 show the current and power curves of the designed PV array at the same levels of the weather conditions. It is clear noticeable the nonlinearity behaviour of the PV panel and array between the output current and the harvested power with respect to PV voltage. At the same time, Fig. 3 and Fig. 4 are confirming the importance of working at the MPP location that to harvest a maximum power.

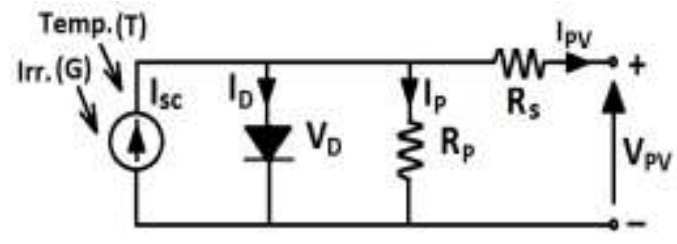

Fig. 2: Equivalent circuit of solar cell. 

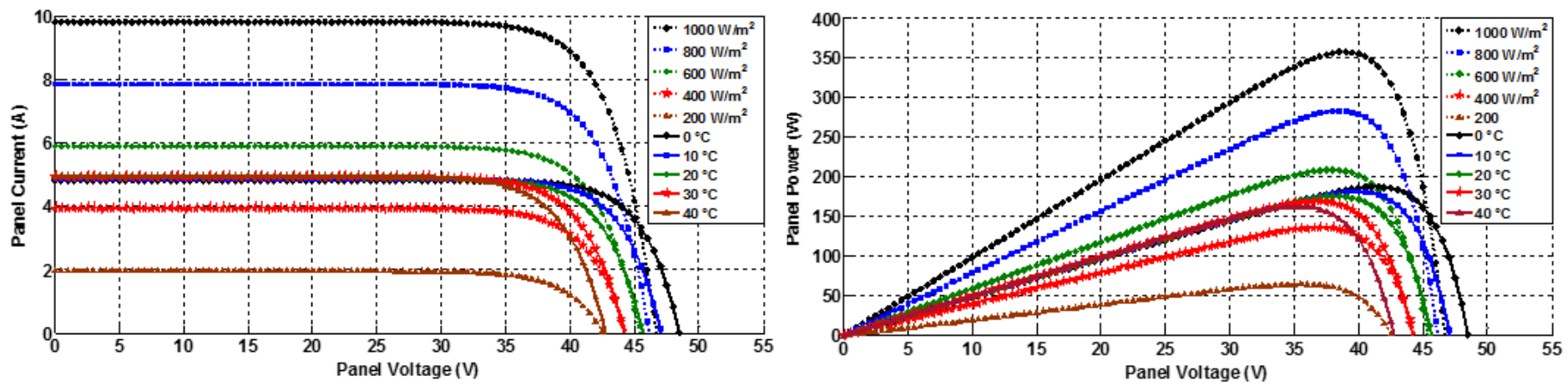

Fig. 3: Panel current and power curves of the PV module SL360TU-36MD at different weather conditions.
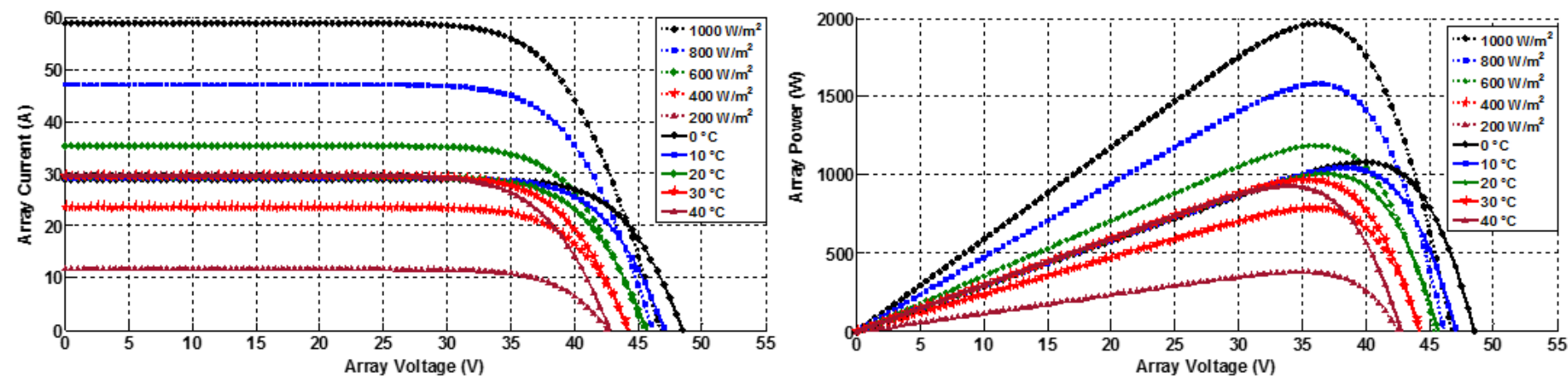

Fig. 4: Array current and power curves of the PV module SL360TU-36MD at different weather conditions.

$$
\begin{gathered}
I_{P V}=I_{S C}-I_{D}-I_{P} \\
I_{S C}=q A G_{r}\left(L_{n}+L_{P}\right) \\
I_{D}=I_{0}\left(e^{\frac{V_{D}}{V_{T}}}-1\right) \\
I_{P}=\frac{V_{D}}{R_{P}} \\
V_{P V}=V_{D}-R_{S} I_{P V} \\
V_{P V \_ \text {Array }}=N_{S} \times V_{P V} \\
I_{P V \_ \text {Array }}=N_{P} \times I_{P V}
\end{gathered}
$$

\subsection{DC-DC Boost Converter}

DC-DC converter is a power electronic circuit working on boosting, bucking, or boosting \& bucking the input DC voltage [8]. Boost converter is designed in this paper to be used for MPPT function based on artificial neural network algorithm. As shown in the full diagram of the proposed system in Fig. 1, the topology of the boost converter is adopted due to the simplicity of the converter design and the controlling function as well. The Continuous Conduction Mode (CCM) is selected as a working mode for the converter, the value of output voltage $V_{o}$ has a linear relation with respect to the value of Duty cycle $(D)$ and input voltage $V_{\text {in }}$ as shown in (8):

$$
V_{o}=\frac{1}{(1-D)} V_{i n}
$$


To have CCM working mode, the value of converter's inductor $L$ should be greater than the condition inductor $L_{C}(9)$ :

$$
L_{C}=\frac{R_{L} D(1-D)^{2}}{2 f_{s}}
$$

where $f_{s}$ is the switching frequency, and $R_{L}$ is the load. The ripple of the output voltage $V_{P P}$ will be within an acceptable level at a large enough $L$, consequently, the minimum converter's capacitor $C_{\min }$ can be determined at a desired $V_{P P}(10)$ :

$$
C_{\text {min }}=\frac{V_{o}-V_{\text {in }}}{R_{\text {max }} V_{p p} f_{s}}
$$

The considered range of the input voltage $V_{\text {in }}$ is from $+5 \mathrm{~V}$ to $45 \mathrm{~V}$, whereas the desired output voltage is around $55 \mathrm{~V}$, and the desired $V_{p p}$ is $2 \%$ of $V_{o}$, the converter design considers a load $R_{L}$ of variation from $50 \%$ to $100 \%$ of full load (50\% to $100 \%$ of rated power). The selected switching frequency $f_{s}$ is $10 \mathrm{kHz}$ that to avoid the negative effect of high switching frequency as a stress on the power electronic switch due to switching losses. The designed parameters of the converter are as follows: $C_{\min }=2273 \mu \mathrm{F}$, and $L_{C}=12.5 \mu \mathrm{H}$, and the selected values of the converter's capacitor and inductor are $3300 \mu \mathrm{F}$, and $0.5 \mathrm{mH}$.

\subsection{Artificial Neural Network Algorithm}

Compared to different conventional algorithms proposed for MPPT function, artificial neural network algorithm is currently proposed in literature as an accurate and fast tracking response algorithm for the MPPT objective. Due to the capability of ANN in accurate predicting of the missing value of any parameters based on learning or training process, from this fact, enough data base for ANN training is required. Based on this merit of ANN predicting capability [14]-[19], ANN is adopted, and algorithm designed for the MPPT objective. ANN estimates the accurate reference voltages for any weather conditions, these reference voltages are representing the instantaneous values of MPP voltages. The ANN algorithm's structure either involves the minimum three layers (input layer, hidden layer, and output layer), or involves more layers by increasing the number of hidden layers. The structure of the neuron is shown in Fig. 5, in which all inputs of $X_{l n}$ to $X_{N n}$ are firstly weighting by $W_{l n}$ to $W_{N n}$ respectively, then adding to the desired value of the Bias $(B)$ using (11). The addition result is passing through an activation function which is either linear, sigmoidal, or hyperbolic transfer function.

$$
Z=\sum_{i=1}^{N} W_{n i} X_{n i}+B
$$

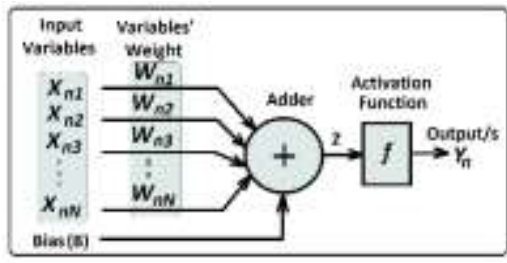

Fig. 5: Neuron Module. 
The adopted type of ANN in this paper is feed forward process through which the weights learning and updating is doing by allowing the signal in forward direction only, and the accuracy of the ANN performance is indicated through the value of the mean square error (MSE) which can be calculated using (12), accurate ANN can be guaranteed at low $M S E$.

$$
M S E=\frac{1}{Q} \sum_{k=1}^{Q} e(k)^{2}
$$

where $Q$ is the input vector's elements, and $e(k)$ is the error. To have ANN's effective performance, enough data are required for ANN training, from this point of view, big range of irradiance $\mathrm{G}\left(\mathrm{W} / \mathrm{m}^{2}\right)$, and also of ambient temperature $\mathrm{T}\left({ }^{\circ} \mathrm{C}\right)$ are used. On the other hand and for better ANN performance, it is recommended that the ranges of input and output variables should be normalized, in other words should be between minimum value of zero and maximum value of one.

\section{Simulation Results}

MATLAB/Simulink is used to do the PV system's simulation and to collect the simulation results. Firstly, ANN block is designed, simulated and accuracy analysed, then inserted in the PV system simulation, and followed by PI. Fig. 6 shows the structure and the performance of the designed ANN algorithm. It is noticeable that the performance of the proposed ANN algorithm has low $M S E$ value which equals to 6.6489 e -5 with small wavy behaviour due to the nature of ANN algorithm. To do accurate evaluating and to demonstrate the positive merits of the proposed solution, system performance is compared with the counterpart of a conventional MPPT algorithm of Perturb \& Observe (P\&O) [23], [27]. The designed PI controller and DC-DC boost converter are involving $P=0.27, I=0.005, C=3.3 \mathrm{mF}, L=0.5 \mathrm{mH}$, and $f_{s}=10 \mathrm{kHz}$ respectively. The simulation period is divided into 8 equal intervals of $0.25 \mathrm{sec}$ to have total testing interval of $2 \mathrm{sec}$. The ANN algorithm and the system are tested with different irradiance levels of increasing trend of $\left(525 \mathrm{~W} / \mathrm{m}^{2}, 600 \mathrm{~W} / \mathrm{m}^{2}, 675 \mathrm{~W} / \mathrm{m}^{2}\right.$, and $\left.750 \mathrm{~W} / \mathrm{m}^{2}\right)$, then decreasing trend of $\left(675 \mathrm{~W} / \mathrm{m}^{2}, 600 \mathrm{~W} / \mathrm{m}^{2}, 525 \mathrm{~W} / \mathrm{m}^{2}\right.$, and $\left.450 \mathrm{~W} / \mathrm{m}^{2}\right)$ with keeping the ambient temperature at $25{ }^{\circ} \mathrm{C}$. Fig. 7 a, and Fig. 7 b show the PV system's performance comparison between ANN and P\&O methods in terms of load power and load voltage respectively, from this figure, it is noticeable the priority of the proposed solution over the conventional one.

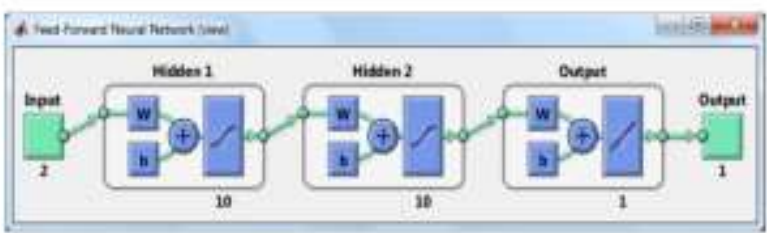

(a)

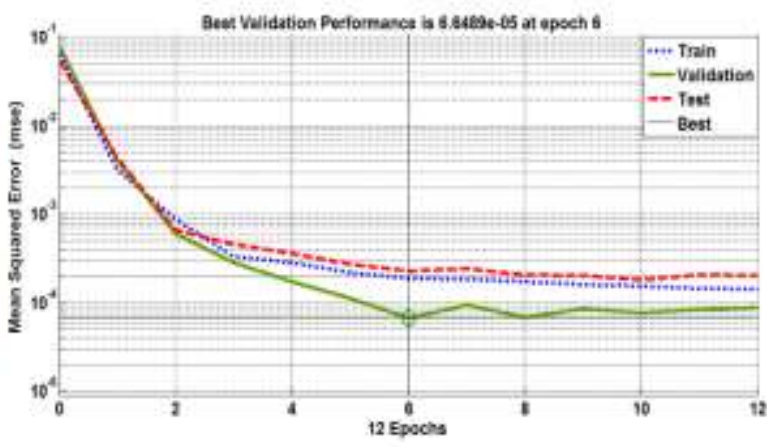

(b)

Fig. 6: Artificial neural network ANN algorithm, (a) ANN algorithm structure, (b) MSE performance. 


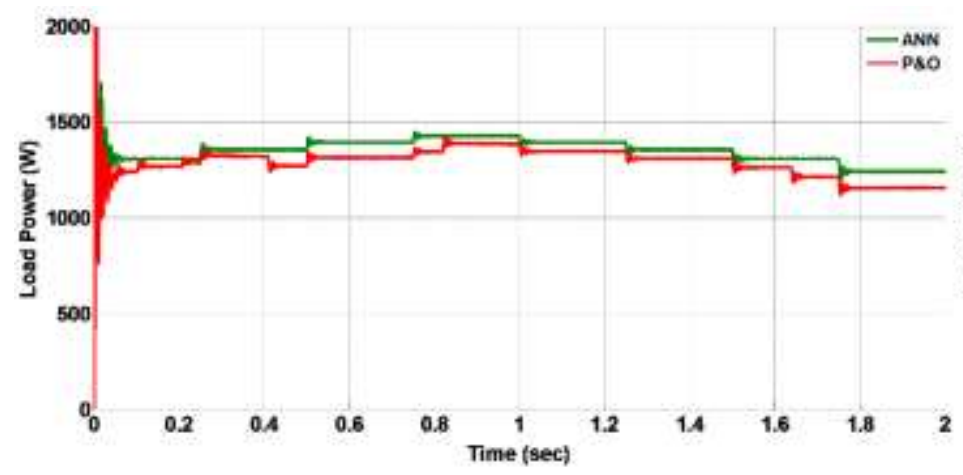

(a)

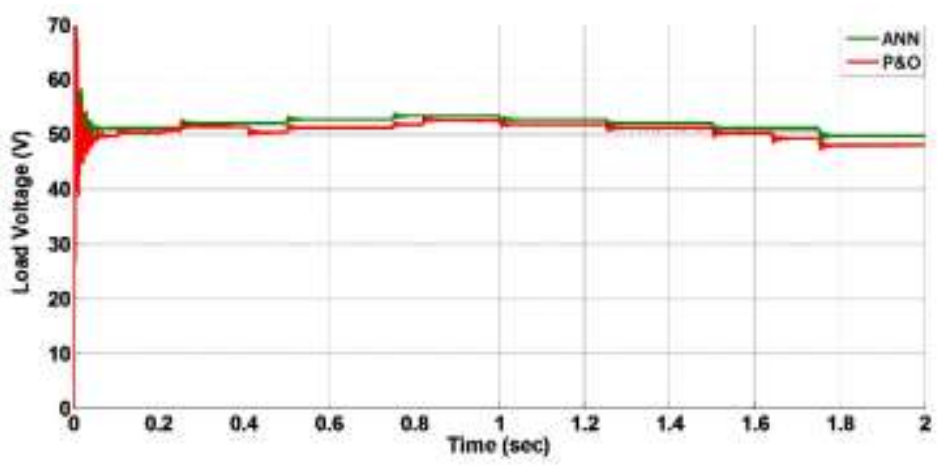

(b)

Fig. 7 a: PV system performance comparison, (a) Load power, (b) Load voltage.

\section{Conclusion}

In this study, a new solution in the direction of integrated PV system for direct current dwelling to the remote places is presented. The solution of $10.8 \mathrm{~kW}$ rated power stand-alone PV system based on artificial neural network is focused on improving system performance in terms of firstly system complexity, and how reducing it and at the same time how reduce the number of system's involved items through applying direct current appliances. The second focusing is how improving the level of delivered power through an effective and fast response algorithm. The proposed solution is started by PV system designing, simulating, then results collecting and analysing. To have accurate evaluation to the proposed solution, system performance is compared with a common used algorithm of $\mathrm{P} \& \mathrm{O}$ for the MPPT function. The collected results are indicating the higher priority of the proposed solution over the conventional one, and promising for a future effective practical prototype

\section{Acknowledgements}

The authors appreciate the financial support provided by school of engineering, American University of Ras $\mathrm{Al}$ Khaimah - UAE, www.aurak.ac.ae/en/school-of-engineering/

\section{References}

[1] Grantham A., Pudney P., Ward L.A., Whaley D., Boland J., "The viability of electrical energy storage for low-energy households," Sol. Energy, vol. 155, pp. 1216-1224, 2017.

[2] Mohler D., Sowder D, "Energy Storage and the Need for Flexibility on the Grid," In Renewable Energy Integration 2nd Edition, Elsevier \& E-Book., 2017, pp. 309-316.

[3] H. A. Attia, T. K. S. Freddy, H. S. Che, W. P. Hew, A. El Khateb, "Confined Band Variable Switching Frequency Pulse Width Modulation (CB-VSF PWM) for Single-Phase Inverter with LCL Filter," IEEE Trans. Power Electronics, vol. 32, iss. 11, pp. $8593-8605$, Nov. 2017.

[4] M. A. Razzak, W. T. Bhuiyan, N. I. Natasha, A. K. M. M. Islam, M. K. M. Amin, "Design of a Grid-connected Photovoltaic Inverter with Maximum Power Point Tracking using Perturb and Observe Technique," IJPEDS, vol. 7 , No. 4, pp. 1212-1220, December 2016,.

[5] Parra D., Swierczynski M., Stroe D. I., Norman S. A., Abdon A., Worlitschek J., O’ Doherty T., Rodrigues L., Gillott M., Zhang X., et al. "An interdisciplinary review of energy storage for communities: Challenges and perspectives," Renew. Sustain. Energy Rev. 79, pp. 730-749, 2017.

[6] Hussain A. Attia, Beza N. Getu, Yousif I. Al-Mashhadany, "Design and Simulation of Dual Axis Solar Tracker for Optimum Solar Energy Absorption," The International Conference on Electrical and Electronics Engineering, Clean Energy and Green Computing (EEECEGC2013), Dubai, UAE, December 2013.

[7] Attia H.A., Getu B.N., "Design \& Simulation of a Solar Tracking System for Optimum Energy Absorption," International Journal of Thermal \& Environmental Engineering, vol. 8, iss. 1, pp. 17-24, 2014. 
[8] Hussain A. Attia, Y. I. Al-Mashhadany, Beza N. Getu, "Design and Simulation of a High Performance Standalone Photovoltaic System, ICREGA'14-Renewable Energy: Generation and Applications, Springer Proceedings in Energy 2014, July 2014.

[9] Abdelaziz Y., Abdallah M., Rafik S., Houari S., "Optimization of partially shaded PV array using a modified P\&O MPPT algorithm," Leonardo Electronic Journal of Practices and Technologies, iss. 28, pp. 179-196, 2016.

[10] T. Noguchi, S. Togashi, R. Nakamoto, "Short-current pulse-based maximum-power-point tracking method for multiple photovoltaic-and-converter module system," IEEE Trans. on Industrial Electronics, vol. 49, no. 1, pp. 217-222, 2002.

[11] M. El Azzaoui, H. Mahmoudi, K. Boudaraia, "Sensorless Fuzzy MPPT Technique of Solar PV and DFIG Based Wind Hybrid System," International Review on Modelling and Simulations (IREMOS), vol. 10, iss. 3, pp. 152-159, 2017.

[12] Hussain A. Attia, Comparative design of fuzzy logic controller for photovoltaic panel maximum power point tracking, International Conference on Electrical and Computing Technologies and Applications (ICECTA' 2017), Ras Al Khaimah, United Arab Emirates, November 2017.

[13] Hussain Attia, "Fuzzy Logic Controller Effectiveness Evaluation through Comparative Memberships for Photovoltaic Maximum Power Point Tracking Function," International Journal of Power Electronics and Drive Systems (IJPEDS), vol. 9, iss. 3, pp. 1147-1156, 2018.

[14] Mona N. Eskander, "Neural Network Controller for a Permanent Magnet Generator Applied in Wind Energy Conversion System," Journal of Power Electronics, vol. 2, no. 1, pp. 46-54, 2002.

[15] R. Haque, "Transmission loss allocation using artificial neural networks, " Master Thesis, University of Saskatchewan Saskatoon, Saskatoon, Canada, 2006.

[16] M. Sadek, M. Elkholy, H. Metwally, "Efficient Operation of Wind Turbine with Doubly Fed Induction Generator Using TLBO Algorithm and Artificial Neural Networks," International Review on Modelling and Simulations (IREMOS), vol. 9, iss. 6, pp. 464-472, 2016.

[17] Mathur D., "Maximum Power Point Tracking with Artificial Neural Network," International Journal of Emerging Science and Engineering (IJESE), vol. 2, iss. 3, 2014.

[18] N. Kalaiarasi, S. Paramasivam, Sanchari Kundu, "Control of Z-Source Inverter Based PV System with MPPT Using ANFIS," International Review on Modelling and Simulations (IREMOS), vol. 7, iss. 5, pp. 797-806, 2014.

[19] Fathi A. O. Aashoor, "Maximum power point tracking techniques for photovoltaic water pumping system," Ph.D. dissertation, Dept. Elect. Elect. Eng., Univ. of Bath, Claverton Down, UK, 2015.

[20] H. Attia, A. Omar, M. Takruri, H. Y. Ali, "Pulse Width Modulation Based Decentralized Street LED Light," International Journal of Power Electronics and Drive System (IJPEDS), vol. 8, iss. 3, pp. 1238-1247, September 2017.

[21] Hussain A Attia, Amjad Omar, Maen Takruri, Design of decentralized street LED light dimming system, 5th International Conference on Electronic Devices, Systems and Applications (ICEDSA'2016), Ras Al Khaimah, United Arab Emirates, December 2016.

[22] YI Al-Mashhadany, HA Attia, "Novel Design and Implementation of Portable Charger through Low-Power PV Energy System", Advanced Materials Research, vol. 925, pp. 495-499, 2014.

[23] Hussain Attia, "A Stand-alone Solar PV System with MPPT Based on Fuzzy Logic Control for Direct Current Portable House Applications" International Review on Modelling and Simulations, 2018.

[24] Hussain Attia, Fernando Gonzalo, "Stand-alone PV System with MPPT Function Based on Fuzzy Logic Control for Remote Building Applications", International Journal of Power Electronics and Drive System, vol. 10, no. 2, June 2019.

[25] Vijay Sharma, BATTERIES, CHARGERS \& ALTERNATORS Excerpt from Inverter Charger Series Manual, SAMLEX AMERICA, [Online]. Available: www.samlexamerica.com

[26] Ali Ibrahim, M.R.I.Ramadan, S. Aboul-Enein, A.Abdel-Azeem ElSebaii, S.M. El-Broullesy, "Short Circuit Current Isc as a Real Non-Destructive Diagnostic Tool of a Photovoltaic Modules Performance", International Journal Of Renewable Energy Research, IJRER, vol.1, no. 3, pp. 53-559, 2011.

[27] Hussain Attia, "Artificial Neural Networks Based Maximum Power Point Tracking Photovoltaic System for Remote Park LED Lighting Applications," International Review on Modelling and Simulations, 2019. 